\title{
ÉDITORIAL
}

\section{Y a-t-il une limite à la phytothérapie ?}

\author{
P. Goetz \\ (C) Lavoisier SAS 2021
}

La première leçon de non-engagement du phytothérapeute aura été ce fameux SARS-Covid-19. Il faut déjà comprendre de quoi il s'agit : maladie liée à une virose avec plus ou moins de développement de virus dans un individu, puis effets du virus (destruction de tissu, blocage de mécanisme fonctionnel, oxydation, etc.).

Avant de proposer un traitement quelconque, il faut savoir ce que l'on veut traiter; or, avec ce fameux virus on est très mal servi. On entre rapidement dans l'inconnu, sans référence scientifique.

Une autre pathologie qui échappe facilement à notre mode de raisonnement, phytothérapie « contre » s'opposant à physiopathologie, est la pathologie endocrinienne. Ici ce n'est pas un problème de diagnostic ou de compréhension de la maladie, mais une question de matériel et de moyen. La médication de phytothérapie d'une insuffisance thyroïdienne ou d'une hyperthyroïdie se résume à quelques rares éléments [1] : Fucus, Laminaria, Inula helenium, Commiphora mukul, Avena sativa, etc. De plus, les effets de ces phytomédicaments se font attendre, et le traitement est rarement inférieur à un ou trois mois. Les associations sont difficiles et mal expérimentées.

Il y a bien une limite à la phytothérapie. L'autre limite de la phytothérapie est constituée par le dosage des simples. Le dosage de l'aubépine (Crataegus oxyacantha) est assez élevé s'il est question d'agir sur l'insuffisance cardiaque de type NYHA 1 ou 2 (le prix du traitement est aussi très important). Il faut comprendre avec cet exemple que la phytothé- rapie est restée souvent à des posologies standard, traditionnelles, et que les doses importantes n'ont pas été tentées. Les formes galéniques, non plus. Souvent, en aromathérapie, on est proche de doses toxiques, et l'expérimentation ne peut s'exercer au-delà de dose « limite ». L'exemple de l'aubépine montre que les essais avec des doses supérieures sont rares. La phytothérapie n'est pas efficace : or, cela est vrai si l'on se borne aux doses inscrites dans le fameux Vidal. Ce sont le plus souvent des mélanges qui ne doivent en rien intervenir de façon risquée, comme pour les doses de Spasmine $^{\circledR}$ ou le Sympathyl ${ }^{\circledR}$. Dans ce dernier cas, quelle est la dose maximale limite du mélange ?

Aubépine, extrait sec de sommité fleurie $75 \mathrm{mg}$

Eschscholtzia, extrait sec $20 \mathrm{mg}$

Et quels sont alors ses effets?

La phytothérapie est-elle sortie de ce que nous a proposé la « teinture-mère » et risque-t-elle de nous offrir d'autres succès thérapeutiques ? Après 40 ans de phytothérapie, je ne désespère pas, mais je pense que cela demande une collaboration qui n'ait pas froid aux yeux d'industriels, de pharmacologues et de médecins cliniciens.

\section{Référence}

1. Goetz P (2021) Phytothérapie de l'hypothyroïdie. Phytothérapie 19:420-5

P. Goetz $(\square)$

DU de phytothérapie, Paris-XIII, F-93017 Bobigny cedex, France

e-mail : goetz.correpondance@gmail.com 